\title{
Effect of ascorbic acid deficiency on serum ferritin concentration in patients with $\beta$-thalassaemia major and iron overload
}

\author{
RWG CHAPMAN, MAM HUSSAIN, A GORMAN, M LAULICHT, DiNA POLITIS,* \\ DM FLYNN, SHEILA SHERLOCK, AV HOFFBRAND

\begin{abstract}
From the Departments of Haematology, Paediatrics and Medicine, Royal Free Hospital, Pond Street, Hampstead, London NW3 $2 Q G$ and ${ }^{*}$ Hellenic Red Cross, Athens, Greece
\end{abstract}

SUMMARY The incidence of ascorbic acid (AA) deficiency and its effect on serum ferritin concentration relative to body iron stores was studied in 61 unchelated patients with $\beta$-thalassaemia major.

Thirty-nine $(64 \%)$ of patients had subnormal leucocyte ascorbate concentrations without clinical evidence of scurvy. The lowest leucocyte ascorbate concentrations tended to occur in the most transfused patients. No correlation was found between the units transfused and serum ferritin concentration in the AA-deficient patients but a close correlation $(r=+0.82 ; p<0.005)$ existed for the AA-replete group. Similarly a close correiation $(r=+0.77 ; p<0.005)$ was obtained between liver iron concentration and serum ferritin in AA-replete patients but only a weak correlation $(r=+0.385 ; p<0.025)$ existed for the AA-deficient group.

When AA-deficient patients were treated with ascorbic acid, serum iron and percentage saturation of iron binding capacity rose significantly; serum ferritin rose in 13 of 21 patients despite the simultaneous commencement of desferrioxamine therapy. In contrast all three measurements tended to fall in AA-replete patients with ascorbic acid and desferrioxamine therapy.

Thus, AA deficiency is commonly present in $\beta$-thalassaemia patients with iron overload and may give rise to inappropriate serum ferritin concentrations in relation to body iron stores.

Ascorbic acid deficiency (AA) causes major abnormalities in iron metabolism in man, including an inappropriately low serum iron concentration in relation to tissue iron stores. ${ }^{1}$ Ascorbic acid deficiency and frank scurvy commonly occur in Bantu patients with dietary iron overload, ${ }^{2}$ and has also been reported in primary haemochromatosis and in transfusional iron overload. ${ }^{3}$

There have been few reports in man on the effect of AA deficiency on serum ferritin concentrations although AA is involved in the incorporation and release of iron from ferritin and in the removal of iron from haemosiderin. 45

Serum ferritin concentration is directly related to body iron stores in normal human subjects, ${ }^{6}$ and has proved to be useful in the diagnosis of iron overload and in monitoring response to therapy. ${ }^{7} 8$ However, raised concentrations of serum ferritin

RWGC is Watson Smith Research Fellow of the Royal College of Physicians of London.

Accepted for publication 2 September 1981 are found in some diseases when body iron stores are not increased, as in acute and chronic liver damage, ${ }^{9}$ malignancy, ${ }^{10}$ megaloblastic anaemia ${ }^{11}$ and infections.

We have now studied the incidence of AA deficiency in patients with $\beta$-thalassaemia major and transfusional iron overload and examined the effect of AA deficiency on the relations between serum ferritin concentration and other parameters of iron overload in these patients. The results show that serum ferritin is a poor measure of iron overload in AA-deficient thalassaemic patients.

\section{Patients and methods}

Sixty-one patients ( 30 male and 31 female, aged 6 to $28 \mathrm{yr}$ ) with $\beta$-thalassaemia major were studied. They had all received regular blood transfusions (mean 164, range 26-408 units) either in Athens or London but had not received regular chelation therapy at the time of study.

Serum ferritin concentration was measured by 
immunoradiometric assay. ${ }^{12}$ Leucocyte ascorbic acid concentration was estimated by the method of Denson and Bowers. ${ }^{13}$ Serum aminotransferase (aspartate transaminase) was measured on the same day as ferritin and leucocyte ascorbate. Serum iron and total iron binding capacity were determined by the method recommended by the ICSH. ${ }^{14}$ Follow-up serum ferritin, iron and iron binding capacity estimations were performed within six months of starting subcutaneous desferrioxamine ${ }^{15}$ ( 2 to $4 \mathrm{~g}$ daily) and oral AA therapy ( $200 \mathrm{mg}$ daily) in 21 initially AA-deficient and six initially AAreplete patients.

Liver biopsies were performed percutaneously in 44 patients using a Menghini needle, and the liver iron concentration measured. ${ }^{16}$ Repeat liver biopsies were performed in 12 patients who were initially AA-deficient, after treatment with oral AA and chelation with subcutaneous desferrioxamine infusions. The data were analysed using Student's paired and unpaired $t$ tests except where stated.

\section{Results}

INCIDENCE OF ASCORBIC ACID DEFICIENCY Thirty-nine $(64 \%)$ of the 61 patients showed leucocyte AA concentrations below the normal range (23-51 $\left.\mu \mathrm{g} / 10^{8} \mathrm{WBC}\right)$. The mean leucocyte AA concentration for all 61 patients was $17 \cdot 7 \mu \mathrm{g} / 10^{8}$ WBC $\pm 1 \cdot 3($ SEM). No patient had clinical evidence of scurvy.

There was no significant difference between the AA-replete and AA-deficient patients with regard to either serum aminotransferase concentrations $(p>0.5)$ or the degree of iron overload as judged by the liver iron concentration $(p>0.5)$ (Table). However, there was a tendency for the liver iron concentration and number of units transfused to be greater in the AA-deficient group (Table). This was confirmed when a significant negative correla- tion $(r=-0.33 ; p<0.01)$ was observed between units of blood transfused and leucocyte AA concentrations.

In order to assess liver iron loading in relation to the units of blood transfused, a ratio was obtained by dividing the liver iron concentration by the number of units transfused (Table). There was no difference in the mean ratios between AA-replete and deficient patients $(p>0.5)$.

\section{SERUM FERRITIN}

A significant but weak correlation $(r=0.42$; $p<0.005)$ was obtained between the serum ferritin and liver iron concentration in the 44 patients who had had liver biopsy (Fig. 1). The positive correlation

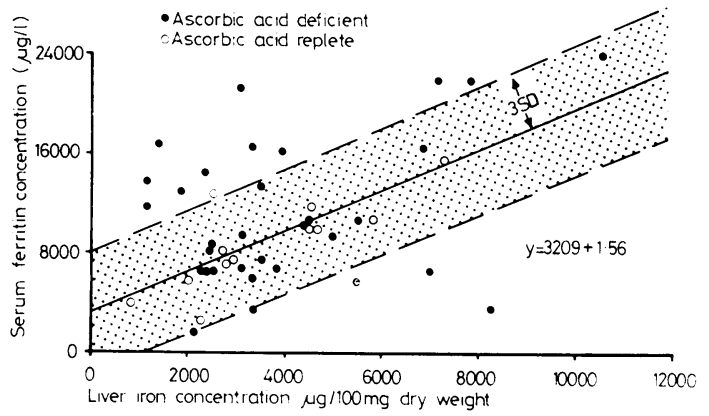

Fig. 1 Serum ferritin plotted against liver iron concentration in thalassaemic patients at presentation. The regression line was obtained using data from ascorbic acid replete patients. - - - represents three standard deviations from the regression line.

became stronger $(r=0.77 ; p<0.005)$ when the 32 AA-deficient patients were excluded (Fig. 1), but weaker for the AA-deficient group alone $(\mathrm{r}=0.395 ; \mathrm{p}<0.025)$. Interestingly the good correlation between serum ferritin and liver iron

Initial laboratory data

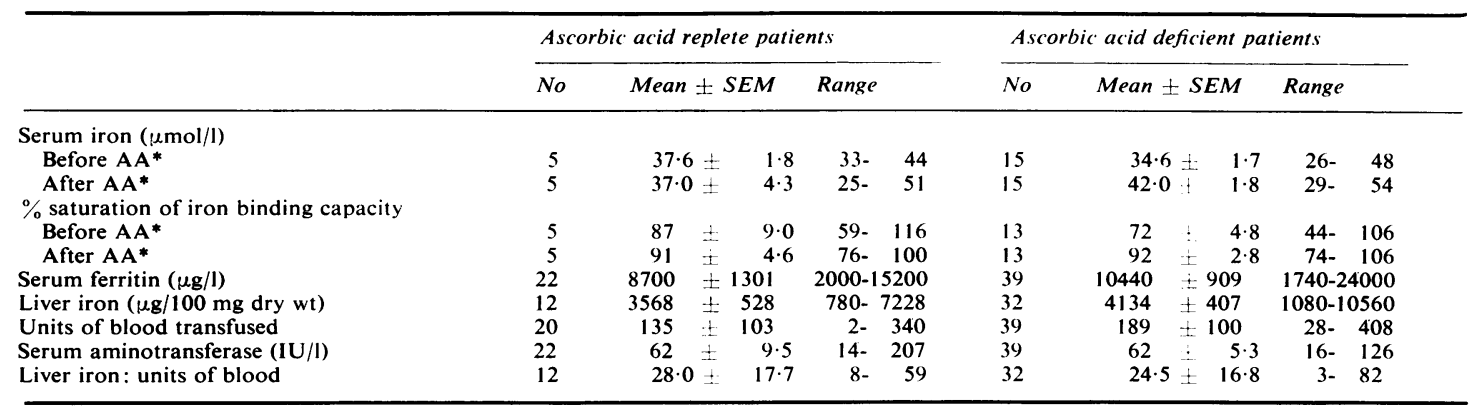

*The results before and after ascorbic acid (and subcutaneous desferrioxamine) therapy are given for serum iron and $\%$ saturation of the iron binding capacity. Other data are initial values only. 
concentration in the AA-replete group, held even in 11 of the patients in whom serum ferritin concentrations exceeded $4000 \mu \mathrm{g} / \mathrm{l}$ (Fig. 1). Eleven of 12 AA-replete patients fell within two standard estimates of the regression line $(y=3209+1.56 \mathrm{x})$ (Fig. 1), whereas only 17 of 32 AA-deficient patients fell within two standard estimates of the same regression line. This difference between the two groups was significant, $\mathrm{p}<0.05, \chi^{2}=4.06$ with Yates' correction. A close correlation $(r=+0.82$; p $<0.0005$ ) was also observed between serum ferritin and units of blood transfused in 20 AA-replete patients, nine of whom had received more than 100 units of blood (Fig. 2), but there was no such correlation in 39 AA-deficient patients $(r=+0.22$; NS). The total units of blood transfused were not known for two AA-replete patients.

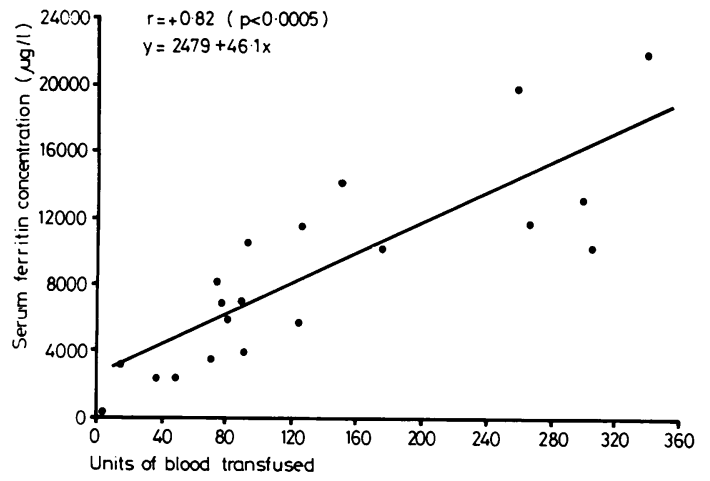

Fig. 2 Serum ferritin plotted against total units of blood transfused in ascorbic acid replete patients.

EFFECTS OF ASCORBIC ACID THERAPY

Despite simultaneous therapy with desferrioxamine there was an increase in serum ferritin concentration during the first six months of AA therapy in 13/21 patients (Fig. 3), although the mean rise was not significant $(t$ test for paired samples, p $>0.20<$ $0 \cdot 5)$. In contrast there was a significant fall in the serum ferritin concentration with chelation and ascorbate treatment in six AA-replete patients $(p<0.025)$. After treatment with AA and desferrioxamine 12 previously AA-deficient patients were rebiopsied from 6-13 months later. A close correlation was then observed between the serum ferritin and liver iron concentration $(r=+0.847 ; p<0.005)$ (Fig. 4), which had not been present at the initial biopsy ( $r=+0.34$; NS).

The serum iron and percentage saturation of the total iron binding capacity rose despite chelation in $13 / 15$ and $11 / 13$ respectively of patients after AA treatment $(t$ test for paired samples $\mathrm{p}<0.02$ for

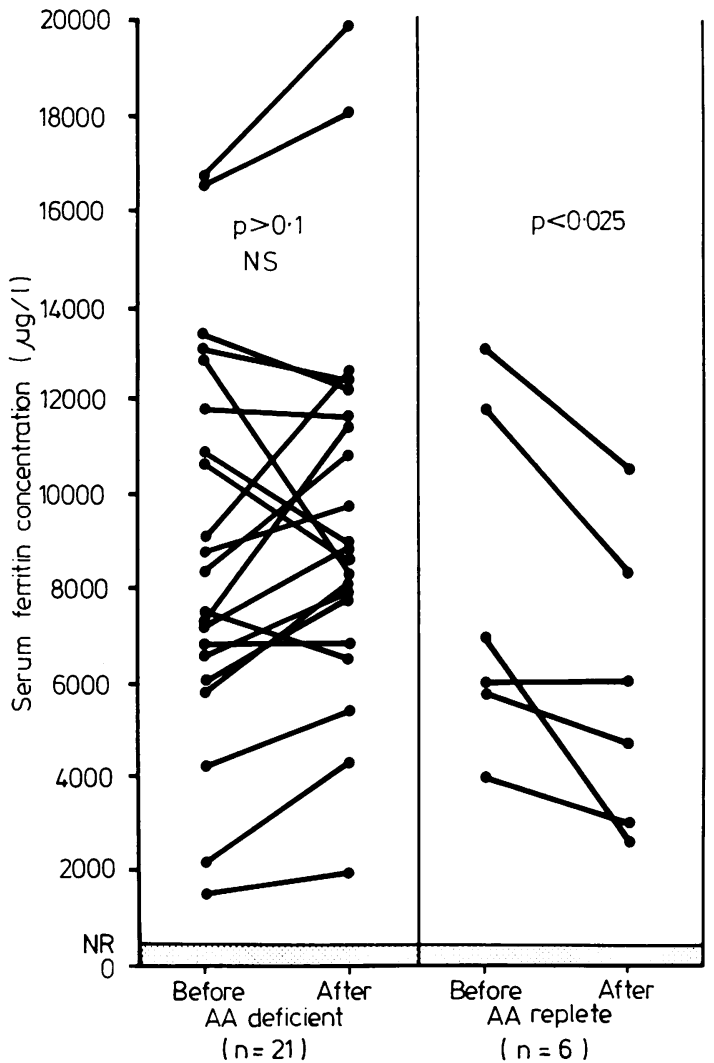

Fig. 3 The effects of ascorbic acid treatment on serum ferritin concentration.

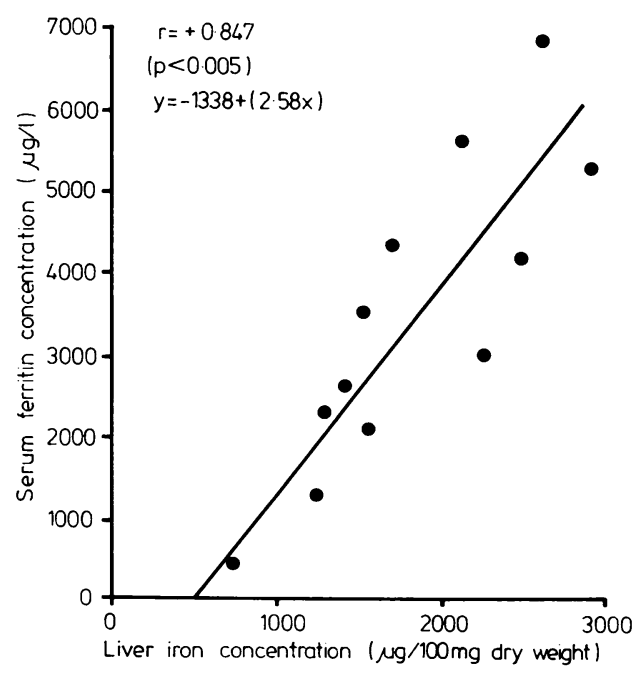

Fig. 4 Serum ferritin plotted against liver iron concentration in previously ascorbic acid deficient patients after ascorbic acid repletion. 
both measurements). In contrast the serum iron and percentage saturation fell with chelation in $3 / 5$ patients who were initially AA-replete (NS).

\section{Discussion}

This study has shown that ascorbic acid (AA) deficiency commonly occurs in $\beta$-thalassaemia major especially in the older and more transfused patients. These results are in keeping with previous studies of patients with idiopathic haemochromatosis, ${ }^{3} 17$ transfusional iron overload ${ }^{3}$ and Bantu siderosis. ${ }^{2}$ It appears, therefore, that both primary or secondary iron overload commonly lead to AA deficiency. In Bantu patients with siderosis the depletion of the vitamin has been shown to be due to accelerated catabolism of ascorbic acid and this has been ascribed to the large amounts of ferric compounds in the tissues. ${ }^{18}$

Ascorbate deficiency causes major abnormalities in human iron metabolism. We have confirmed that in iron-loaded AA-deficient thalassaemic patients, like siderotic Bantu, ${ }^{2}$ the serum iron is inappropriately low in relation to tissue iron stores and rises to appropriate concentrations with AA treatment. Ascorbate deficiency also leads to an increased concentration of haemosiderin and decreased ferritin content in cells. ${ }^{23}$ These changes can be rapidly reversed by the administration of AA. In the guinea pig, AA has been shown to be involved in the incorporation and release of iron from ferritin. ${ }^{4}$

The results here show that in the presence of AA deficiency the serum ferritin concentration does not correlate with body iron stores, assessed by liver iron concentration or by units of blood transfused. The normally close correlation shown by Letsky et $a l^{19}$ can be restored by AA repletion. These inappropriate concentrations of serum ferritin in the AA-deficient group could not be ascribed to variation in liver damage, which is known to affect serum ferritin concentrations as the activities of aminotransferase were similar in the AA-deficient and replete patients.

The exact effect of AA therapy on serum ferritin concentration was difficult to assess since we commenced desferrioxamine chelation simultaneously with AA in all patients. This was essential in view of the suggested toxicity of AA therapy alone in iron-loaded thalassaemic patients. ${ }^{20}$ Since desferrioxamine lowers serum ferritin in patients with thalassaemia major within a few months ${ }^{21}$ it was impossible, therefore, to elucidate the effect of AA therapy alone on serum ferritin in these patients.

In our AA-replete patients there was a close relation between the serum ferritin concentration and iron stores, irrespective of the level of serum ferritin or the total number of units of blood transfused. Worwood et al ${ }^{22}$ showed that in thalassaemic patients a simple relation between serum ferritin and iron stores cannot be assumed when ferritin concentrations exceed $4000 \mu \mathrm{g} / \mathrm{l}$ or in patients who have received more than 100 units of blood. As shown in the present study, however, this breakdown in relations may be due to concomitant AA deficiency in the more iron-loaded patients. Indeed the correlation coefficient obtained from our regression line of serum ferritin against units of blood transfused in AA replete patients who have received more than 100 units is similar to that found by Letsky et $a l^{19}$ and Worwood et $a l^{22}$ for patients who had received less than 100 units of blood. Patients who have received more than 100 units of blood are likely to be AA-deficient which may explain the flattening of the regression line ${ }^{19}$ and the poor correlation between the serum ferritin and iron stores $^{22}$ previously observed in such patients, and which was not seen in our AA-replete group. It has been suggested that the flattening of the regression line is caused by the secretion of glycosylated ferritin reaching a maximum with increasing iron accumulation. ${ }^{22}$ AA deficiency may, therefore, selectively reduce the secretion of glycosylated ferritin, perhaps by reducing its synthesis but this remains to be established.

There have been few reports on the effects of AA deficiency on serum ferritin. AA deficiency in the guinea pig causes serum ferritin concentrations to fall inappropriately and blocks the rise in serum ferritin level in response to iron loading. ${ }^{23}$ Cohen et $a^{24}$ reported an AA-deficient $\beta$-thalassaemic woman with clinical evidence of scurvy whose serum ferritin increased threefold on AA replacement therapy. They suggested that AA deficiency may be beneficial in iron overload by leading to preferential storage of iron in the reticuloendothelial system rather than the parenchymal cells of the liver and heart where the effects of iron are more toxic. We have not confirmed that AA deficiency leads to relative sparing of parenchymal iron deposition, at least assessed by liver iron concentration since the ratio of liver iron concentration to total numbers of units transfused was not significantly lower in the AA-deficient patients, compared with the AA-replete group.

The present study shows that AA deficiency in thalassaemia major is related to the number of units of blood transfused, and causes an inappropriate serum ferritin in relation to tissue iron stores. The mechanism by which serum ferritin concentrations are affected by AA remains uncertain. At all events it is important to assess AA status in all 
patients with gross iron overload if serum ferritin is to be used to assess the degree of iron overload and to monitor the effectiveness of chelation therapy.

\section{References}

${ }^{1}$ Bothwell TH, Bradlow BA, Jacobs P, et al. Iron metabolism in scurvy with special reference to erythropoiesis. $\mathrm{Br} J$ Haematol 1964;10:50-8.

${ }^{2}$ Wapnick AA, Bothwell TH, Seftel M. The relationship between serum iron levels and ascorbic acid stores in siderotic Bantu. Br J Haematol 1970;19:271-6.

${ }^{3}$ Wapnick AA, Lynch SR, Krawitz P, Seftel HC, Charlton RW, Bothwell TH. Effects of iron overload on ascorbic acid metabolism. Br Med J 1968 ;iii:704-7.

${ }^{4}$ Lipschitz DA, Bothwell TH, Seftel HC, et al. The role of ascorbic acid in the metabolism of storage iron. $\mathrm{Br} J$ Haematol 1971;20:155-63.

${ }^{5}$ Schwartz E, Cohen A. Iron chelation and the role of ascorbic acid. In: Proceedings of the Fourth International Symposium of Proteins of Iron Storage and Transport. Davos Switzerland, April 1979.

- Walters GO, Miller FM, Worwood M. Serum ferritin concentration and iron stores in normal subjects. $J$ Clin Pathol 1973;26:770-2.

${ }^{7}$ Beamish MR, Walker R, Miller F, et al. Transferrin iron, chelatable iron and ferritin in idiopathic haemochromatosis. Br J Haematol 1974;27:218-28.

8 Batey RG, Hussein S, Sherlock S, Hoffbrand AV. The role of serum ferritin in the management of idiopathic haemochromatosis. Scand J Gastroenterol 1978;13: 953-7.

- Prieto J, Barry M, Sherlock S. Serum ferritin in patients with iron overload and with acute and chronic liver diseases. Gastroenterologv 1975;68:525-33.

10 Worwood M. Serum ferritin. CRC Crit Rev Clin Lab Sci 1979;10:171-204.

${ }^{11}$ Hussein S, Laulicht M, Hoffbrand AV. Serum ferritin in megaloblastic anaemia. Scand J Haematol 1978;20: 241-5.

12 Addison GM, Beamish MR, Hales CN, Hodgkins M, Jacobs A, Llewellin P. An immunoradiometric assay for ferritin in the serum of normal subjects and patients with iron deficiency and iron overload. J Clin Pathol $1972 ; 25: 326-9$.
${ }^{13}$ Denson KW, Bowers EF. The determination of ascorbic acid in white cells. A comparison of WBC ascorbic acid and phenolic acid excretion in elderly patients. Clin Sci 1961:21:157-62.

14 International Committee for Standardisation in Haematology (Iron Panel). The measurement of total and unsaturated iron binding capacity in serum. Recommendation for measurement of serum iron in human blood. Br J Haematol 1978;38:281-94.

${ }^{15}$ Hussain MAM, Green N, Flynn DM, Hoffbrand AV. Effect of dose, time and ascorbate on iron excretion after subcutaneous desferrioxamine. Lancet 1977;i: 977-9.

${ }^{16}$ Barry M, Sherlock S. Measurement of liver iron concentration in needle biopsy specimens. Lancet 1971 ; i:100-3.

${ }^{17}$ Brissot P, Deugnier Y, Le Treut A, et al. Ascorbic acid status in idiopathic haemochromatosis. Digestion 1978;17:479-87.

${ }^{18}$ Lynch SR, Seftel HC, Torrance JD, Charlton RW, Bothwell TH. Accelerated oxidative catabolism of ascorbic acid in siderotic Bantu. Am J Clin Nutr 1967; 20:641-7.

${ }^{19}$ Letsky EA, Miller F, Worwood M, Flynn DM. Serum ferritin in children with thalassaemia regularly transfused. J Clin Pathol 1974;27:652-5.

${ }^{20}$ Nienhuis AS. Vitamin C and iron. N Engl J Med 1981; 304:170-1.

21 Hoffbrand AV, Gorman A, Laulicht M, et al. Improvement in iron status and liver function in patients with transfusional iron overload with long-term subcutaenous desferrioxamine. Lancet 1979;i:947-9.

22 Worwood M, Cragg SJ, Jacobs A, et al. Binding of serum ferritin to concanavalin A: patients with homozygous $\beta$-thalassaemia and transfusional iron overload. $B r J$ Haematol 1980;46:409-16.

${ }^{23}$ Roeser HP, Halliday JW, Sizemore DJ, Nikles A, Willgoss D. Serum ferritin in ascorbic acid deficiency. Br J Haematol 1980;45:457-66.

${ }^{24}$ Cohen A, Cohen L, Schwartz E. Scurvy and altered iron stores in thalassaemia major. $N$ Engl J Med 1981;304: 158-60.

Requests for reprints to: Professor AV Hoffbrand, Department of Haematology, Royal Free Hospital, Hampstead, London NW3 2QG, England. 